\title{
Comparing Efficiency of Web Based Learning Contents on Different Media
}

\author{
doi:10.3991/ijet.v4s3.1087 \\ J. Lapuh Bele ${ }^{1,2}$, J. Rugelj ${ }^{2}$ \\ ${ }^{1}$ B2 d.o.o., Ljubljana, Slovenia \\ ${ }^{2}$ University of Ljubljana, Ljubljana, Slovenia
}

\begin{abstract}
We tried to find out what kind of multimedia learning materials gave the most efficient and effective results with regards to learning time and knowledge gained. Different web based learning materials were used as regards presentation mode: static pictures, animations with online text and animations with narrated text. Although the research results showed that learners from WBL contents with static graphics learnt less time than learners from animations, we did not find significant differences in learning time between experimental groups. However, we proved significant differences between three experimental groups in terms of gained knowledge. The learners using learning materials with static graphics performed worse than learners using materials with animations. Furthermore, we did not prove significant differences in gained knowledge between groups that learnt from audio animations and the animations with online text.
\end{abstract}

Index Terms-multimedia learning, web-based learning, animations

\section{INTRODUCTION}

Web based learning contents (WBLC) that enable learners to gain or improve computer literacy (e.g. Word, Excel) contains many instructions which can be illustrated by captured screenshots. Each instruction can be presented with a sequence of static pictures or with an animation.

Visual and audio presentation of learning material is highly important as it can enhance learning or impede it with counterproductive overload of sensory channels [8],[9],[11]. Multimedia goes beyond visual presentation. It is an extremely important and essential element of efficient WBLCs and requires special attention. Research during the past two decades has produced mixed results about the effects of multimedia on learning [6]. The inconsistencies are most likely due to the fact that there are multiple factors operating, as has been proposed in the integrated model of multimedia learning [8]. According to Betrancourt (2005), in many cases animation does not add any benefit in comparison with static graphic. Based on the modality principle (i.e. present animation and audio narration rather than animation and on-screen text), recommended by Mayer (2001), the best learning results of learners are expected when learning from audio animations. However, in the preliminary research, we asked learners what kind of verbal presentation of information they preferred in animations. According to their answers, $28 \%$ of them preferred audio narration, $33 \%$ online text and $38 \%$ favoured audio narration plus online text [7]. However, the question is if preferred presentations of learners are also the most suitable for them? In Slovenia, movies and foreign TV programmes are not synchronised and people are used to reading subtitles.

Do factors like this influence predisposition of learners to different types of presentation of learning material?

Therefore, we wanted to find out what kind of graphic presentation of learning material provide the most efficient and effective learning results.

\section{THEORETICAL FRAMEWORK}

The use of multimedia tools must be carefully planned in order to avoid a counterproductive overload of sensory channels. In recent times, cognitive psychology has progressed and many of the major findings in this field have been of use in instructional design of multimedia educational materials. Mayer (2001) presented a cognitive theory of multimedia learning, which is based on dual coding theory, cognitive load theory and constructivist learning theories [8],[9],[11]. Miller (1956) found out that human working memory is limited. People process visual and verbal information (e.g. narrated and online text) in separate cognitive channels, which run simultaneously [2],[11]. Considering these theories, Mayer suggests a set of seven design principles [9]:

- Multimedia: Present words and pictures rather than words alone. Words can be narrated or printed.

- Modality: Present animation and audio narration rather than animation and on-screen text.

- Redundancy: Use animation and narration rather than animation, narration and on-screen text.

- Coherence: Exclude extraneous words, pictures and sounds.

- Spatial contiguity: Present corresponding words and pictures near rather than far from each other.

- Temporal contiguity: Present corresponding words and pictures simultaneously rather than successively.

Mayer's principles were established in the context of numerous experimental studies where students had to learn about simple mechanical systems such as brakes and pumps. However, it can be assumed that some subjects can hardly be presented depictive. Schnotz \& Bannert [11] indicate that presenting graphics is not always beneficial for the acquisition of knowledge. Their study suggests that pictures facilitate learning if individuals have low prior knowledge and if the subject matter is visualized in a taskappropriate way [9],[12].

When considering the implications of the principles, it is important to be aware of circumstances that may impact their application. These circumstances can include the 
capability of learner's hardware to support audio, his hearing ability, cognitive abilities and whether the physical learning environment is appropriate for audio.

Some researchers think that people have different learning styles considering sensory abilities. They call them VAK learning styles [3]. The VAK learning style uses the three main sensory receivers: visual, auditory, and kinesthetic (movement) to determine the dominant learning style. It is sometimes known as VAKT (Visual, Auditory, Kinesthetic, \& Tactile) [5]. Learners use all three modalities to receive and learn new information and experiences. However, according to the VAK or modality theory, one or two of these receiving styles is normally dominant. VAK is derived from the accelerated learning world and seems to be about the most popular model nowadays due to its simplicity, however, its main weakness is that research does not support it [2]. This is probably because it is more of a preference, rather than a style.

In the preliminary research we asked learners what kind of verbal presentation of information they preferred in animations. They filled the questionnaire after attending the e-learning course in which they were able to choose among the animations with narrated and animations with textual explanations. $28 \%$ of them preferred audio narration, $33 \%$ online text and $38 \%$ favoured audio narration plus online text [7].

In Slovenia, movies and TV programmes in foreign languages are not synchronised. Therefore people are used to reading subtitles. The ability and the manner of reading subtitles are very strong. Many people say they even read English subtitles in Slovene movies. However, they also say they cannot read subtitles and listen to the narration simultaneously.

According to Betrancourt (2005), in many cases animation does not add any benefit in comparison with static graphic, that is illustrated with a sequence of static pictures allowing learners to learn at their own pace. Animation can be badly designed, causing cognitive overload [13].

The main question of our research was, what kind of graphic presentation of learning material (i.e. sequence of static pictures, animation with narrated text, animation with online text) provide the most efficient and effective learning results. We set the following experimental hypothesis: "There are statistically significant differences among learning results (i.e. learning time, gained knowledge) between learners using different presentation modes (i.e. static pictures, audio animation, online text animation)". We expected that learners from WBLCs with animations would need less time to learn and gain more knowledge than learners from WBLC with static pictures. However, we did not know what type of animations would give the best learning outcomes.

\section{METHOD}

\section{A. Materials}

Three types of e-learning courses were observed in our experiment. In all of them, the learning content was the same. The courses were different as regards to presentation mode: static pictures, animations with online text and animations with narrated text (i.e. audio animations). Students learned how to create charts using MS Excel. Elearning courses were accessible via the internet and LMS system eCampus.
Each WBLC has 40 learning pages, 18 questions for formative knowledge evaluation and a test for summative knowledge evaluation with automatic feedback. WBLCs with animations have 19 animations each. WBLC with static pictures have 53 static pictures (i.e. on average 2.8 pictures per animation).

\section{B. Procedure}

The experiment was carried out in a laboratory environment (i.e. appropriately equipped computer classroom). 96 basically digitally literate participants took part in the research. As the classroom has 15 computers, the experiment was carried out seven times. In each experiment session we repeated the same procedure.

In the beginning of the course, we tested participants to measure their pre-knowledge of Excel basics and chart design using Excel. We used a questionnaire that was previously verified with item analysis. According to Bloom's taxonomy, we measured knowledge and understanding with the pre-test.

Then we divided participants into three equal groups according to their previous knowledge (i.e. learners with static pictures, learners with online text animations, learners with audio animations). As proven later in this article, there were no statistically significant differences among the groups according to previous knowledge.

Participants could use up to 90 minutes for learning from the assigned learning content. We measured time of learning for each participant using technology available in the e-learning environment. After the learning we tested participants again to find out how much knowledge they gained. According to Bloom's taxonomy, we measured the application of knowledge.

Participant could get from 0 to 100 points at the pre test and at the final test.

\section{Participants}

Participants were adult volunteers who attended the cost free e-learning course "How to create charts using MS Excel".

\section{Measurements}

The measurement instruments were pre-knowledge test, knowledge test and the learning time which was recorded in the LMS.

Independent variables were code of participant, gender, age, and presentation mode.

Dependent variables were learning time; the pre-test result, the test result, and gained knowledge (i.e. calculated difference between test result and pre-test result).

\section{E. Results}

We set the following null hypothesis: "There are no statistically significant differences among learning results (i.e. learning time, gained knowledge) among learners using different presentation mode (i.e. static pictures, audio animation, online text animation)".

The hypothesis was tested using the analysis of variance (ANOVA).

\section{1) Participants}

37 males $(38.5 \%)$ and 59 females $(61.5 \%)$ participated in the research. Their mean age was 31 . 


\section{2) Pre-knowledge test results}

Participants achieved from 0 to 89 points on the scale from 0 to 100 points. The descriptive statistic of the groups formed after the test, is presented in the next table (TABLE I.

TABLE I.

DESCRIPTIVE STATISTICS OF THE PRE-KNOWLEDGE TEST

\begin{tabular}{|l|c|c|c|c|c|c|}
\hline $\begin{array}{l}\text { Presentation } \\
\text { mode }\end{array}$ & N & Mean & $\begin{array}{c}\text { St. } \\
\text { dev. }\end{array}$ & $\begin{array}{c}\text { St. } \\
\text { error }\end{array}$ & Min & Max \\
\hline Online text anim. & 32 & 42.8 & 24.1 & 4.3 & 0 & 89 \\
Audio anim. & 32 & 41.7 & 22.2 & 3.9 & 0 & 83 \\
Static pictures & 32 & 40.6 & 24.4 & 4.3 & 0 & 86 \\
\hline Total & 96 & 41.7 & 23.4 & 2.4 & 0 & 89 \\
\hline
\end{tabular}

\section{3) Learning time}

We tested the following experimental hypothesis: there are statistically significant differences in learning times among learners using different presentation mode (i.e. static pictures, audio animation, online text animation).

Participants could learn up to 90 minutes. We measured learning times using the reports available in the LMS.

Descriptive statistics shows the following results (TABLE II. ).

TABLE II.

DESCRIPTIVE STATISTICS OF LEARNING TIMES

\begin{tabular}{|l|c|c|c|c|c|c|}
\hline $\begin{array}{l}\text { Presentation } \\
\text { mode }\end{array}$ & N & Mean & $\begin{array}{c}\text { St. } \\
\text { dev. }\end{array}$ & $\begin{array}{c}\text { St. } \\
\text { error }\end{array}$ & Min & Max \\
\hline $\begin{array}{l}\text { Online text } \\
\text { anim. }\end{array}$ & 32 & 64.3 & 18.3 & 3.2 & 24 & 93 \\
Audio anim. & 32 & 64.2 & 14.0 & 2.5 & 36 & 91 \\
Static pictures & 32 & 56.2 & 17.6 & 3.1 & 30 & 93 \\
\hline Total & 96 & 61.5 & 17.0 & 1.7 & 24 & 93 \\
\hline
\end{tabular}

Learning times were rather dispersed: from 24 to 93 minutes. On average, participants learning from WBLC with static pictures learnt less time than others. On average, they spent 56 minutes. Participants that learnt from WBLCs with animations spent almost an equal amount of time: 64 minutes.

Tests Kolmogorov-Smirnov and Shapiro-Wilk (TABLE III. ) were significant $(\mathrm{p}>0.05)$. We could conclude that the data distribution in each group is not significantly different from a normal distribution.

TABLE III.

TESTS OF NORMALITY

\begin{tabular}{|l|c|c|c|c|c|c|}
\hline \multirow{2}{*}{$\begin{array}{c}\text { Presentation } \\
\text { mode }\end{array}$} & \multicolumn{3}{|c|}{$\begin{array}{c}\text { Kolmogorov- } \\
\text { Smirnov }\end{array}$} & \multicolumn{3}{c|}{ Shapiro-Wilk } \\
\cline { 2 - 7 } & Stat. & df & Sig. & Stat. & df & Sig. \\
\hline online text anim. &, 140 & 32 &, 112 &, 956 & 32 &, 207 \\
audio anim. &, 122 & 32 &, 200 &, 966 & 32 &, 406 \\
static pictures &, 084 & 32 &, 200 &, 957 & 32 &, 232 \\
\hline
\end{tabular}

Therefore, we could apply the one-way ANOVA test. First we checked the homogeneity of variances (TABLE IV. ).
TABLE IV.

HOMOGENEITY OF VARIANCES TEST

\begin{tabular}{|c|c|c|c|}
\hline Levene statistics & df1 & df2 & Sig. \\
\hline 1.490 & 2 & 93 & 0.231 \\
\hline
\end{tabular}

As Levene's statistics had significance $p>0.05$, we could accept the homogeneity of variances assumption and carried out the ANOVA procedure to find out if there are statistically significant differences among the experimental groups (TABLE V. ).

TABLE $\mathrm{V}$.

ANOVA TEST RESULTS FOR LEARNING TIMES

\begin{tabular}{|l|c|c|c|c|c|}
\hline & $\begin{array}{c}\text { Sum of } \\
\text { Squares }\end{array}$ & df & $\begin{array}{c}\text { Mean } \\
\text { Square }\end{array}$ & F & Sig. \\
\hline Between Groups & 1392.27 & 2 & 696.14 & 2.49 & 0.09 \\
Within Groups & 26045.56 & 93 & 280.06 & & \\
Total & 27437.83 & 95 & & & \\
\hline
\end{tabular}

According to the significance $\mathrm{p}>0.05$, we conclude that the differences among groups are not significantly different. We could not reject the following null hypothesis: there are no statistically significant differences among learning times among learners using different presentation mode (i.e. static pictures, audio animation, online text animation).

$$
\mathrm{F}(2,93)=2.486, \mathrm{p}>0.05 \text {. }
$$

Although on average learners using WBLC with static graphics spent less time than those who learnt from the WBLCs with animations, the differences among the groups are not statistically significant.

Before the research, we expected that learning from the WBLC with the animations would be more effective and efficient than learning from WBLC with static pictures, as we can explain the subject using dynamic multimedia. It seems that running the animations took some time. Learners from WBLC with static graphic read the content at their own pace, probably too quickly and payed not enough attention to the pictures. As we will see in the following, they also gained less knowledge than learners from WBLCs with animations.

\section{4) Gained knowledge}

We tested the following experimental hypothesis: there are statistically significant differences in gained knowledge among learners using different presentation mode (i.e. static pictures, audio animation, online text animation).

As participants had different pre-knowledge, we decided to measure learning results with the difference between the results of the test and pre-test. We called this variable gained knowledge.

Participants could achieve up to 100 points on both tests. The difference could be negative. The next table (TABLE VI. ) shows that some students performed worse on the test than on the pre-test. However, we have to point out that the pre-tests were on a different level (i.e. understanding), according to Bloom's taxonomy, than the test (i.e. application).

The next table (TABLE VI. ) shows that learners from audio animations achieved the best results. Their mean of gained knowledge was the highest. Learners from online text animations performed almost as well as learners form 
audio animations. However, learners from WBLC with static pictures achieved the worst learning results, measured by the difference between test and pre-test results.

TABLE VI.

DESCRIPTIVE STATISTICS FOR GAINED KNOWLEDGE

\begin{tabular}{|l|c|c|c|c|c|c|}
\hline $\begin{array}{c}\text { Presentation } \\
\text { mode }\end{array}$ & N & Mean & $\begin{array}{c}\text { St. } \\
\text { Dev. }\end{array}$ & $\begin{array}{c}\text { St. } \\
\text { error }\end{array}$ & Min & Max \\
\hline Online text anim. & 32 & 33.3 & 33.8 & 6.0 & -31 & 95 \\
Audio anim. & 32 & 36.4 & 29.3 & 5.2 & -30 & 100 \\
Static pictures & 32 & 12.2 & 40.2 & 7.1 & -65 & 85 \\
\hline Total & 96 & 27.3 & 36.0 & 3.7 & -65 & 100 \\
\hline
\end{tabular}

The chart shows the difference among groups (Fig. 1).

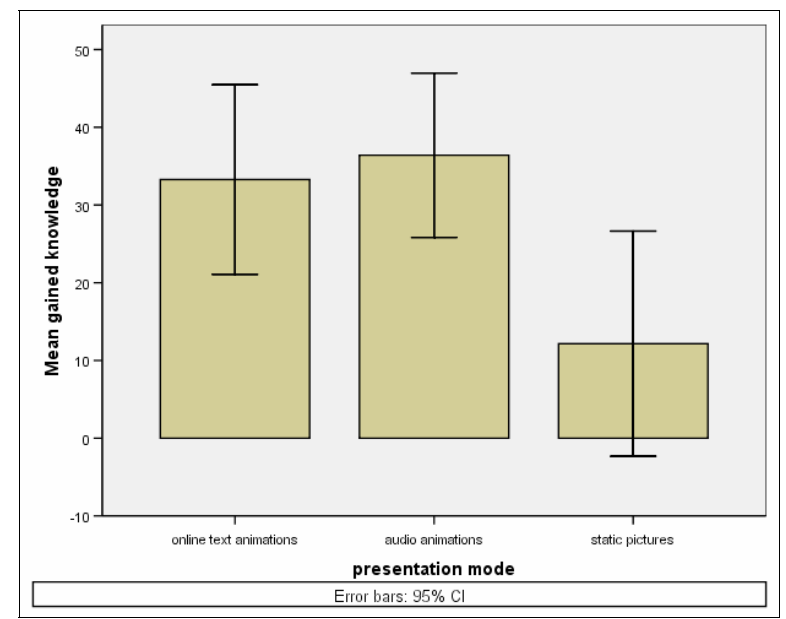

Figure 1. Means of learning results according to the presentation mode

Before running the ANOVA we tested the assumption of normality and the assumption of homogeneity of variances.

Based on the Kolmogorov-Smirnov test we found out that the data distribution in each group is not statistically significantly different from normal distribution. Then we checked the homogeneity of variances with Levene's statistics (TABLE VII. ).

TABLE VII.

HOMOGENEITY OF VARIANCES TEST

\begin{tabular}{|c|c|c|c|}
\hline Levene statistics & df1 & df2 & Sig. \\
\hline 2.018 & 2 & 93 & 0.139 \\
\hline
\end{tabular}

As Levene statistics had significance $p>0.05$, we could accept the homogeneity of variances assumption and carried on the ANOVA procedure to find out if there are statistically significant differences among the experimental groups (TABLE VIII. ).

TABLE VIII.

ANOVA FOR GAINED KNOWLEDGE

\begin{tabular}{|l|c|c|c|c|c|}
\hline & $\begin{array}{c}\text { Sum of } \\
\text { Squares }\end{array}$ & df & $\begin{array}{c}\text { Mean } \\
\text { Square }\end{array}$ & F & Sig. \\
\hline Between Groups & 11137.0 & 2 & 5568.50 & 4.62 & 0.012 \\
Within Groups & 112104.4 & 93 & 1205.42 & & \\
\hline Total & 123241.4 & 95 & & & \\
\hline
\end{tabular}

As the significance was $\mathrm{p}<0.05$, we conclude that the differences among groups are significant. We could reject the null hypothesis and accept the experimental hypothesis: there are statistically significant differences in gained knowledge among learners using different presentation mode (i.e. static pictures, audio animation, online text animation).

$$
\mathrm{F}(2,93)=4.620, \mathrm{p}<0.05 \text {. }
$$

Descriptive statistics shows that groups learning from WBLCs with animations gained more knowledge than the groups learning from WBLC with static pictures. It is obvious that the difference among groups is caused by presentation mode - static pictures. Therefore we used contrast test and Tukey HSD post hoc test to find out the differences among groups that learnt from animations.

We chose following contrast coefficients to observe the results of groups learning from animations (TABLE IX. ).

TABLE IX.

CONTRAST COEFFICIENTS

\begin{tabular}{|c|c|c|c|}
\hline \multirow{3}{*}{ Contrast } & \multicolumn{3}{|c|}{ presentation mode } \\
\cline { 2 - 4 } & online text anim. & audio anim. & static pictures \\
\hline 1 & 1 & -1 & 0 \\
\hline
\end{tabular}

The contrast test shows no statistically significant differences among groups learning between WBLCs with online text animations and WBLCs with audio animations (TABLE X. ).

TABLE X.

CONTRAST TEST

\begin{tabular}{|c|c|c|c|c|c|c|}
\hline & $\begin{array}{c}\text { Con- } \\
\text { trast }\end{array}$ & $\begin{array}{c}\text { Value of } \\
\text { contrast }\end{array}$ & $\begin{array}{c}\text { St. } \\
\text { error }\end{array}$ & t & df & $\begin{array}{c}\text { Sig. } \\
\text { (2-tailed) }\end{array}$ \\
\hline $\begin{array}{c}\text { equal } \\
\text { variances }\end{array}$ & 1 & -3.13 & 8.68 & -0.36 & 93 & 0.72 \\
\hline
\end{tabular}

The procedure Tukey HSD compares pairs of groups (TABLE XI. ).

TABLE XI.

TUKEY HSD MULTIPLE COMPARISONS

\begin{tabular}{|l|l|c|c|c|}
\hline $\begin{array}{l}\text { (I) } \\
\text { presentation } \\
\text { mode }\end{array}$ & $\begin{array}{l}\text { (J) } \\
\text { presentation } \\
\text { mode }\end{array}$ & $\begin{array}{c}\text { Mean } \\
\text { differ. } \\
\text { (I-J) }\end{array}$ & $\begin{array}{c}\text { Std. } \\
\text { error }\end{array}$ & Sig. \\
\hline \multirow{2}{*}{ online text anim. } & audio anim. & -3.1 & 8.7 & .93 \\
& static pictures & 21.1 & 8.7 & .04 \\
\hline \multirow{2}{*}{ audio anim. } & online text anim. & 3.1 & 8.7 & .91 \\
& static pictures & 24.3 & 8.7 & .02 \\
\hline \multirow{2}{*}{ static pictures } & online text anim. & -21.1 & 8.7 & .04 \\
& audio animations & -24.3 & 8.7 & .02 \\
\hline
\end{tabular}

Based on ANOVA and Tukey HSD the following results were found:

- There are statistically significant differences in gained knowledge among learners using different presentation mode (i.e. static pictures, audio animation, online text animation).

- There are no statistically significant differences in gained knowledge among learners learning from WBLC with audio animation and those learning from WBLC with online text animations.

- There are statistically significant differences in gained knowledge among learners learning from 
WBLC with audio animations and those learning from WBLC with static pictures.

- There are statistically significant differences in gained knowledge among learners learning from WBLC with online text animations and those learning from WBLC with static pictures.

\section{CONCLUSIONS}

The main question of our research was, what kind of graphic presentation of learning material (i.e. sequence of static pictures, the animation with narrated text, the animation with online text) provides the most efficient and effective learning results (i.e. learning time, gained knowledge). We set the experimental hypothesis that there are statistically significant differences among learning results (i.e. learning time, gained knowledge) between learners using different presentation mode (i.e. static pictures, audio animation, online text animation). We expected that learners from WBLCs with animations would learn less time and gained more knowledge than learners from WBLC with static pictures. However, we did not know what type of animations would give the best learning results.

The experiment showed that learners from WBLC with static pictures spent the least amount of time and gained the least knowledge. Although on average learners using WBLC with static graphics spent less time than those learning from the WBLCs with animations, the differences among the groups are not statistically significant. Therefore we could not conclude that learning from WBLCs with static graphics is the most time efficient.

We also found that learners from audio animations achieved the best results in gained knowledge. Furthermore, learners from WBLC with online text in animations performed almost as well as learners form WBLC with animations with audio. However, the differences among all three groups were statistically significant and showed the worst results for learners with static graphics. Further investigation showed significant differences among pairs of groups: learners with static pictures and learners with audio animations, learners with static pictures and learners with online text animations, but no statistical differences among groups of learners that learnt from WBLC with animations.

Based on the research results we recommend authors to design WBLCs with both types of animations (i.e with audio and with online text) and let the learner choose which one he/she prefers.

At the end, we have to point out that we had small samples (i.e. 32 people in each experimental group). The research took place in Slovenia where people are used to reading subtitles. The preliminary research showed that learners like both, audio animations and online text animations. However, we do not know if people actually prefer learning materials that are most suitable for them. Therefore, it would be interesting to repeat the research inviting students from different countries and taking into account cultural diversity.

\section{REFERENCES}

[1] Betrancourt, M. The Animation and Interactivity Principles in Multimedia Learning. V: R. Mayer (Ed.), The Cambridge handbook of Multimedia learning.Cambridge University Press, New York, 2005

[2] Baddeley. A. D. Working memory. Oxford, England: Oxford University Press, 1986.

[3] Bandler, R. Using Your Brain - for a CHANGE. Real People Press, 1985..

[4] Coffield, F., Moseley, D., Hall, E., Ecclestone, K. Learning styles and pedagogy in post 16 learning. A systematic and critical review. Available online 01.11.2006: http://www.lsda.org.uk/ files/PDF/1543.pdf

[5] Dunn, R, Dunn, K. Teaching students through their individual learning styles: A practical approach. Reston, VA: Reston Publishing Company, 1978.

[6] Hede, T., Hede, A., Multimedia effects on learning: Design implications of an integrated model, ASET, 2002, http://www.ascilite.org.au/aset-archives/confs/2002/hede-t.html

[7] Lapuh Bele, J., Rugelj, J. Efficient learning from multimedia webbased learning contents. V: MÉNDEZ-VILAS, A. Current developments in technology-assisted education, Vol. 1. [Badajoz: Formatex, cop. 2006], 2006.

[8] Mayer, R. E., Multimedia learning, Cambridge University Press, New York, 2001

[9] Mayer, R. E., The Cambridge Handbook of Multimedia Learning, Cambridge University Press, New York, 2005.

[10] Miller, G. A. The Magical Number Seven, Plus or Minus Two: Some Limits on Our Capacity for Processing Information. The Psychological Review, 63, p. 81-97,1956. (doi:10.1037/h0043158)

[11] Paivio, A. Mental representations: A dual coding approach. Oxford, England: Oxford University Press, 1986.

[12] Schnotz, W., Bannert, M., Construction and Interference in Learning from Multiple Representation, Learning and instruction, 13,2003

[13] Sweller, J. Implications of Cognitive Load Theory for Multimedia Learning. V: R. Mayer (Ed.), The Cambridge handbook of Multimedia learning (p. 19-30). New York: Cambridge University Press, 2005.

\section{AUTHORS}

J. L. Bele is with the B2 Vocational College, Ljubljana, Slovenia (e-mail: julija.bele@b2.eu).

J. Rugelj is with the University of Ljubljana, Faculty of education, Ljubljana, Slovenia (e-mail: joze.rugelj@ pef.uni-lj.si).

This article was modified from a presentation at the International Conference of Interactive Computer Aided Learning ICL2009, September 2009 in Villach, Austria. Submitted 08 October 2009. Published as resubmitted by the authors on 2 November 2009 . 